\title{
Health Related Quality of Life among Omani Men and Women with Type 2 Diabetes
}

\author{
Melba Sheila D'Souza, ${ }^{1}$ Ramesh Venkatesaperumal, ${ }^{1}$ Susan D. Ruppert, ${ }^{2}$ \\ Subrahmanya Nairy Karkada, ${ }^{3}$ and Devakirubai Jacob ${ }^{1}$ \\ ${ }^{1}$ Department of Adult Health and Critical Care, College of Nursing, Sultan Qaboos University, 123 Muscat, Oman \\ ${ }^{2}$ The University of Texas Health Science Center at Houston School of Nursing, Houston, TX 77030, USA \\ ${ }^{3}$ Department of Business Studies, Higher College of Technology, 123 Al-Khuwair, Oman
}

Correspondence should be addressed to Melba Sheila D'Souza; melba123@rediffmail.com

Received 16 November 2014; Revised 4 April 2015; Accepted 6 May 2015

Academic Editor: Nitin Gupta

Copyright (C) 2016 Melba Sheila D’Souza et al. This is an open access article distributed under the Creative Commons Attribution License, which permits unrestricted use, distribution, and reproduction in any medium, provided the original work is properly cited.

The aim of this study was to explore predictors of health related quality of life (HRQoL) among men and women with type 2 diabetes. This cross-sectional descriptive study consisted of a random sample of 300 adults with type 2 diabetes in a selected public hospital. Euro-QoL and Revised Summary of Diabetes Self-Care Activities scales were used to collect data between January and June 2010. Schooling and ability to manage positively were highly significant predictors of quality of life (QoL) among women as compared to men. Age, prevention of activities of daily living and knowledge/management of diabetes were significant predictors of Health state among women as compared to men. Findings demonstrate that $30.6 \%$ (versus $35.7 \%$ ) of the variance in the total QoL and 14\% (versus 23\%) of the variance in health state could be explained by personal and clinical characteristics among women and men, respectively. The study underlines the importance for nurse educators to assess HRQoL among men and women and to develop effective self-care management strategies based on personal and clinical characteristics.

\section{Introduction}

Diabetes mellitus (DM) is a chronic progressive metabolic disorder due to absolute (type 1) or relative (type 2) deficiency of insulin hormone [1]. Worldwide, 366 million people were estimated to have diabetes mellitus in the year 2011, and numbers are predicted to double by 2030 [2-4]. DM has caused approximately 4.6 million deaths in the age group of 20-79 years in a ten-year period from 2001 to 2011, accounting for approximately $8.2 \%$ of mortality $[5,6]$. Almost $80 \%$ of deaths related to diabetes occur in low- and middle-income developing countries [7]. The incidence of type 2 diabetes (T2D) with an early onset associated with complications has risen in recent years in Oman compared to other Middle East countries [8-10]. The impact of T2D may limit function and quality of life among men and women. Individuals with T2D need a disciplined balance between the demands of self-care and preferred lifestyles.
Type 2 diabetes is developing into an international public health problem, with a significant increase in the Middle East region $[6,11]$. In Oman, the prevalence of T2D escalated from $11.6 \%$ (2000) to $15 \%$ (2005) and rose to $16.1 \%$ (2010), with rising prevalence among all age groups $[12,13]$. These figures are expected to double by 2030 [11] due to the life threatening long term complications $[14,15]$ and substantial impact on health and well-being [16-18]. A significant number of Omani men and women lack knowledge, skills, and information on self-care management while coping with T2D [8]. Hence, an exploration of personal and clinical factors to improve selfcare behaviors among Omani men and women with T2D is important in assisting them in managing their health.

\section{Review of Literature}

Health related quality of life (HRQoL) is a multidimensional construct with bearing on a person's physical, cognitive, 


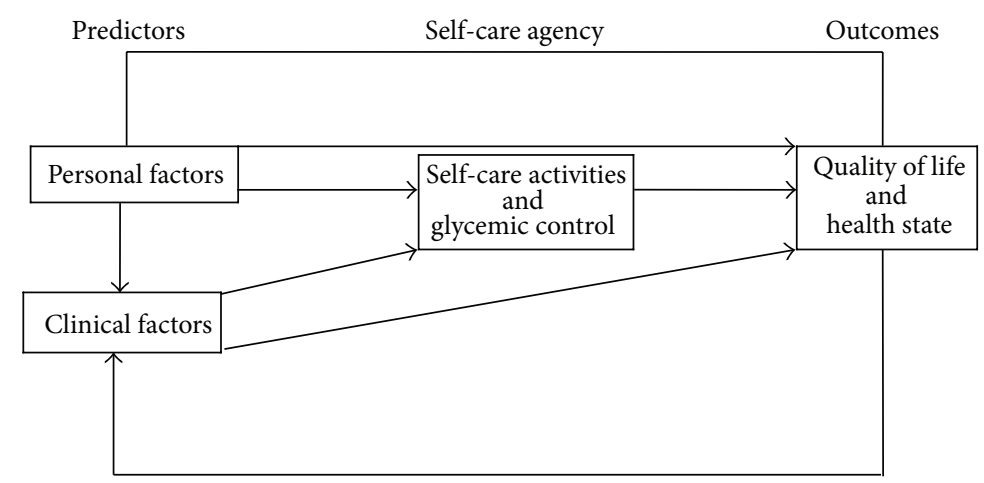

FIGURE 1: Health related quality of life among adults with type 2 diabetes (adapted from Sousa et al. [33]).

social, emotional, psychological, role, and spiritual status $[19,20]$. HRQOL is an acceptable outcome or efficacy of self-care among adults with T2D (Figure 1). The literature on perceptions of living with T2D is extensive and has been shown to correlate with quality of life (QoL) [21, 22]. Several studies show that adults with T2D rate their QoL lower than the general population [23-26] as compared to those with type 1 diabetes (T1D) $[27,28]$. Women with T2D have been found to have a lower quality of life than men [29-31], and those with a longer duration of T2D had poor QoL [32]. A self-care management model [33] leads to better glycemic control [34] and QoL [35], while those with poor glycemic control were found to have low QoL $[36,37]$. No studies focusing on the predictors of QoL and health status among Omani men and women have been reported. Hence, the purpose of this study was to examine the predictors of QoL and health state and to examine comparisons among Omani men and women.

\section{Material and Methods}

3.1. Design. A cross-sectional descriptive study was conducted among adults with T2D in the outpatient diabetes clinic in a selected public hospital.

3.2. Sample/Participants. A sampling framework list of the accessible population with known type 2 diabetes $(N=2000)$ was obtained from the diabetes clinic in a selected public tertiary hospital in Oman. A simple random sampling using random number tables was used to recruit Omani adults who were screened in this diabetes clinic. The inclusion criteria were adults above 18 years diagnosed with T2D for two years who were able to understand, communicate, and converse in Arabic or English language and were not currently pregnant. The exclusion criteria were adults with known diagnosis of T1D, unknown T2D, cognitive/neurological impairment, mental/physical disability, or critical or advanced complications.

Sample size was estimated with the $\mathrm{G}^{*}$ Power software at a power of 0.95 with an effect size of 0.15 using 10 predictors (independent variables), an alpha of 0.05 , and standard deviation of $1 \%$ on two-tailed testing $[38,39]$. To obtain a power of 0.95 and assuming a $30 \%$ incompletion rate, a total sample size of 330 was required for these input parameters. Subsequently, a random sample of 330 adults with T2D was recruited.

3.3. Measurement. A review of the literature was conducted to select standardized instruments to measure the identified concepts of HRQoL and health/self-care activities. Two instruments were reviewed and selected. Physiological indicators were used to assess diabetes control and body weight. The sociodemographic and clinical-related information was primarily gathered by a demographic and clinical baseline tool which included age, gender, schooling (educational level), duration of diabetes, diabetes education, knowledge and management, ability to manage, activities of daily living, and medication.

Health related quality of life was evaluated with the EuroQol (EQ-5D) [40, 41]. The EQ-5D-5L consists of five dimensions (mobility, self-care, usual activities, pain/discomfort, and anxiety/depression). Each dimension had five levels: no problems, slight problems, moderate problems, severe problems, and extreme problems. The EQ visual analog scale (VAS) then recorded the respondent's self-rated health on a 20 centimeter (10-point interval) vertical VAS with endpoints categorized as "the best health you can imagine" and "the worst health you can imagine." Worst imaginable health state was recorded as 0 at the bottom of the scale, and best imaginable health state was achieved as 100 at the top. Both the 5-item index score and the VAS score were then converted into a value score between 0 ("worst health state") and 1 ("best health state") $[24,40]$.

Self-care activities (SCA) were evaluated with the Revised Summary of Diabetes Self-Care Activities Scale (SDSCA) to assess aspects of the diabetes regimen and evaluate the dietary management skills of the participants. The SDSCA scale is a self-reporting measure of the frequency of performing 13 diabetes self-care tasks and consisted of six subscales of the diabetes self-management (DSM) behaviors: diet, exercise, blood glucose testing, medication taking, foot care, and smoking behavior over the prior seven days [42]. Interitem correlations had a range of $r=0.20-0.76$ (mean $=0.47)$ for four SDSCA subscales and 6-month test-retest reliability had a range of $r=0.00-0.58($ mean $=0.40)$ [42]. 
The glycosylated or glycated hemoglobin (HbAlc) value was classified into good glycemic control if the HbAlc values are less than or equal to $(\leq) 7 \%$ and poor glycemic control if $\mathrm{HbAlc}$ values are greater than $(>)$ 7\%. Glycemic control of $\leq 7.0 \%$ is endorsed as a treatment goal $[17,43]$. Body mass index (BMI) in weight in kilograms/square of height in meters $\left(\mathrm{Kg} / \mathrm{m}^{2}\right)$ was categorized as underweight if $\leq 18.5 \mathrm{Kg} / \mathrm{m}^{2}$, normal if $18.5-24.9 \mathrm{Kg} / \mathrm{m}^{2}$, overweight if $25-$ $29.9 \mathrm{Kg} / \mathrm{m}^{2}$, and obese if $\geq 30 \mathrm{Kg} / \mathrm{m}^{2}$ [44]. Weight and height were measured by a portable digital scale and a portable stadiometer.

3.4. Validity and Reliability. The EQ-5D, SDSCA, and demographic and clinical characteristics instruments were translated to Arabic and back-translated and checked with monolingual testing. No discrepancies were found between the original and linguistic translated versions of the instruments. The linguistic validation of the Arabic version of the tools was found to be adequate. The final instruments used in this study were administered to 30 Omani adults with T2D twice in a 2week interval. Intraclass correlation coefficient was intended to evaluate the test-retest reliability for the subdimensions of the EQ-5D (0.75 and 0.91). Interitem correlations had a range of $r=0.75-0.86$ for four SDSCA subscales and itemto-total correlations had a range of $0.77-0.91$ for the SDSCA. Good evidence for internal consistency was shown using Cronbach's alpha for the SDSCA which demonstrated $\alpha=$ 0.87 , which was considered acceptable.

3.5. Data Collection. Data were collected using EQ-5D and SDSCA standardized questionnaires after the pilot study between January and June 2010 among 330 adults with T2D in the diabetes clinic. Study participants were provided with an explanation of the study, and informed consent was obtained. Ethical approval was provided by the Ethics and Research Committee, College of Nursing at Sultan Qaboos University. Informed written and verbal consent was acquired from each participant who met the inclusion criteria through a written letter. Confidentiality was retained between the investigator and the participant. Informed consent and the completed questionnaires were stored and kept in locked cabinets. During the study, 30 selected adults dropped from the study. A $91 \%(N=300)$ completion response rate was obtained.

\section{Data Analysis and Results}

Study surveys and biological samples were labeled with a unique study identifier. Coded data files were kept separately from the code list to maintain anonymity. The Statistical Packages for Social Sciences (SPSS) was used for analysis. A probability of $<0.05$ was considered statistically significant. Descriptive and inferential statistics were calculated using the SPSS statistical package version 21.0 (SPSS Inc., Chicago, IL, USA). A normality test and multicollinearity checks were performed. The determinants of QoL were assessed with ANOVA and multivariate generalized linear model (GLM)/MANOVA [45-48]. Predictors were determined for MANOVA using important determinants from ANOVA [47].
4.1. Demographic and Clinical Characteristics (Table 1). The highest percent of Omani men was between 50-59 years (40.6\%) as compared to $21.7 \%$ among the women (Table 1 ). The highest frequency of adherence to self-care activities was an average of three days/week among men (61.5\%) and women (60.5\%). A higher percentage of the men (62.2\%) had poor $\mathrm{HbAlc}$ values as compared to women $(46.5 \%)$.

For men, $30.1 \%$ reported that T2D mostly prevented their activities of daily living as compared to $26.8 \%$ reported among the women. Nearly half percentage of the women $(53.5 \%)$ and men $(50.3 \%)$ had moderate ability to manage diabetes positively. More women (79.6\%) were on prescribed oral hypoglycemic agents as compared to men (70.6\%); while the remaining participants were on insulin.

4.2. Predictors of QoL and Health State among Men and Women (Tables 2-5). Women had slightly higher mean QoL scores $(p<0.05)$ for age, schooling, prevention of activities of daily living, ability to manage positively, and knowledge of diabetes and its management as compared to men (Table 2). Women had higher mean health state scores for age and prevention of activities of daily living and knowledge of diabetes and its management as compared to men. Schooling and ability to manage positively were highly significant predictors of QoL among women $(p<0.05)$ as compared to men. Age, prevention of activities of daily living and knowledge/management of diabetes were significant predictors of Health state among women as compared to men. Ability to manage diabetes positively was a significant predictor of health state among men as compared to women.

Schooling and ability to manage diabetes positively were significant with QoL among women; while age, prevention of activities of daily living, and knowledge of diabetes and management were significant with health state among women as compared to men (Table 2). Ability to manage diabetes positively was significant with health state among men compared to women.

Women had higher mean QoL scores for duration of diabetes, diabetes education, and medication as compared to men (Table 3). Positively higher perception on health state scores was found with duration of diabetes, SCA, diabetes education, medication, BMI, and HbAlc among women. SCA and medication were highly significant predictors of health state among women; while BMI was highly significant among men. SCA and medication were significant with health state among women; while BMI was significant with health state among men (Table 3). In this study, quality of life and health state were interdependent variables. MANOVA models were used with all determinants emerging from the ANOVA tests as predictors of QoL and health state (Tables 2-5). These personal and clinical characteristics interact with the specific domains valued as important in life, which explains the significant differences in QoL and health state among Omani men and women.

A further GLM technique was useful to explore the relationship between QoL and health state, interdependent variables with the predictors (like age and duration of diabetes) as seen in Tables 4 and 5. The combined effect of predictors on QoL and health state using Wilks's lambda multivariate 
TABLE 1: Personal and clinical characteristics among Omani men and women $(N=300)$.

\begin{tabular}{|c|c|c|c|c|c|c|}
\hline \multirow{2}{*}{ Number } & \multirow{2}{*}{ Variables } & \multirow{2}{*}{ Categories } & \multicolumn{2}{|c|}{ Men $N=143$} & \multicolumn{2}{|c|}{ Women $N=157$} \\
\hline & & & Frequency & Percent & Frequency & Percent \\
\hline \multirow{4}{*}{1} & \multirow{4}{*}{ Age (years) } & $30-39$ & 18 & 12.6 & 29 & 18.5 \\
\hline & & $40-49$ & 39 & 27.3 & 64 & 40.8 \\
\hline & & $50-59$ & 58 & 40.6 & 34 & 21.7 \\
\hline & & $60 \&$ above & 28 & 19.6 & 30 & 19.1 \\
\hline \multirow{4}{*}{2} & \multirow{4}{*}{ Schooling } & Until 8th grade & 35 & 24.5 & 59 & 37.6 \\
\hline & & High school & 59 & 41.3 & 58 & 36.9 \\
\hline & & Diploma & 48 & 33.6 & 38 & 24.2 \\
\hline & & Technical & 1 & 0.7 & 2 & 1.3 \\
\hline \multirow{7}{*}{3} & \multirow{7}{*}{$\begin{array}{l}\text { Knowledge of } \\
\text { diabetes and its } \\
\text { management }\end{array}$} & Poor & 14 & 9.8 & 2 & 1.3 \\
\hline & & Fair & 11 & 7.7 & 14 & 8.9 \\
\hline & & Satisfactory & 26 & 18.2 & 25 & 15.9 \\
\hline & & Above average & 22 & 15.4 & 43 & 27.4 \\
\hline & & Good & 55 & 38.5 & 51 & 32.5 \\
\hline & & Very good & 14 & 9.8 & 16 & 10.2 \\
\hline & & Excellent & 1 & 0.7 & 6 & 3.8 \\
\hline \multirow{3}{*}{4} & \multirow{3}{*}{ Duration of diabetes } & $0-9$ & 57 & 39.9 & 55 & 35.0 \\
\hline & & $10-19$ & 67 & 46.9 & 77 & 49.0 \\
\hline & & $20 \&$ above & 19 & 13.3 & 25 & 15.9 \\
\hline \multirow{2}{*}{5} & \multirow{2}{*}{$\begin{array}{l}\text { Self-care activities } \\
\text { (SDSCA) }\end{array}$} & 0-3 days/week & 88 & 61.5 & 95 & 60.5 \\
\hline & & 4-7 days/week & 55 & 38.5 & 62 & 39.5 \\
\hline \multirow{2}{*}{6} & \multirow{2}{*}{ Diabetes education } & No & 50 & 35.0 & 65 & 41.4 \\
\hline & & Yes & 93 & 65.0 & 92 & 58.6 \\
\hline \multirow{3}{*}{7} & \multirow{3}{*}{$\begin{array}{l}\text { Body mass index } \\
\left(\mathrm{kg} / \mathrm{m}^{2}\right)\end{array}$} & $<18.5 /$ Underweight & 4 & 2.8 & 4 & 2.5 \\
\hline & & 18.5-24.9/Healthy weight & 96 & 67.1 & 106 & 67.5 \\
\hline & & 25.0-29.9/Overweight & 43 & 30.1 & 47 & 29.9 \\
\hline \multirow{2}{*}{8} & \multirow{2}{*}{ HbAlc (\%) } & $<7.0 \%$ & 54 & 37.8 & 84 & 53.5 \\
\hline & & $>7.0 \%$ & 89 & 62.2 & 73 & 46.5 \\
\hline
\end{tabular}

tests (Table 4) shows duration of diabetes, prevention of activities of daily living, and ability to manage positively were significant predictors of QoL and health state among men as compared to women.

The test of overall model significance (Table 5) showed the model is important for each dependent variable (QoL and health state). MANOVA models were used with all independent variables in the ANOVA tests as predictors of QoL and health state (Table 5). MANOVA results are explained with the test of overall model significance and the test of overall individual effects of predictors. Among women with $\mathrm{T} 2 \mathrm{D}, 30.6 \%$ of the variance in the total QoL and $14 \%$ of the variance in health state could be explained by personal and clinical characteristics (Table 5), while $35.7 \%$ of the variance in the total QoL and $23 \%$ of the variance in health state was explained by personal and clinical characteristics among men. These $R^{2}$ values indicated a supportive relationship among the predictors of QoL and health state. QoL and health state scores were strongly correlated with the age, diabetes duration, and prior diabetes education. Hence, personal and clinical characteristics had a significant positive effect on QoL and health state supporting the self-care diabetes management model.

"Tests of between-subjects effects" (Table 5) apply an F test of significance to the relation of each covariate (age, diabetes duration, SCA, diabetes education, ability to manage positively, and BMI) in relation to each of the dependent variables (QoL and health state). Age and diabetes education were significant predictors of QoL, and SCA was a significant predictor of health state among women as compared to men. Duration of diabetes, diabetes education, ability to manage diabetes positively, and BMI were significant predictors of health state among men as compared to women.

\section{Discussion}

Higher schooling, increased ability to manage diabetes, higher age, moderate level of prevention of activities of daily living, higher knowledge of diabetes and management, higher SCA, and use of medication among women influenced their QoL and health state as compared to men. This state contributed to an increased QoL and health among women as 
TABLE 2: Personal characteristics and total QoL and health state among men and women.

\begin{tabular}{|c|c|c|c|c|c|c|c|c|c|}
\hline \multirow{2}{*}{ Determinants } & \multirow{2}{*}{ Categories } & \multicolumn{2}{|c|}{ Men's QoL } & \multicolumn{2}{|c|}{ Women's QoL } & \multicolumn{2}{|c|}{ Men's health state } & \multicolumn{2}{|c|}{ Women's health state } \\
\hline & & Mean & $\mathrm{Sig} / p$ & Mean & $\mathrm{Sig} / p$ & Mean & $\mathrm{Sig} / p$ & Mean & $\mathrm{Sig} / p$ \\
\hline \multirow{4}{*}{ Age } & $30-39$ & 12.22 & \multirow{4}{*}{$0.000^{*}$} & 12.38 & \multirow{4}{*}{$0.000^{*}$} & 69.44 & \multirow{4}{*}{0.523} & 76.38 & \multirow{4}{*}{$0.000^{*}$} \\
\hline & $40-49$ & 10.05 & & 10.45 & & 69.36 & & 67.34 & \\
\hline & $50-59$ & 8.93 & & 8.50 & & 70.09 & & 73.09 & \\
\hline & $60 \&$ above & 9.29 & & 8.73 & & 66.61 & & 66.33 & \\
\hline \multirow{4}{*}{ Schooling } & Until 8th grade & 9.89 & \multirow{4}{*}{0.482} & 9.85 & \multirow{4}{*}{$0.002^{*}$} & 67.86 & \multirow{4}{*}{0.425} & 70.76 & \multirow{4}{*}{0.895} \\
\hline & High school & 9.90 & & 11.07 & & 70.68 & & 69.66 & \\
\hline & Diploma & 9.35 & & 8.84 & & 68.02 & & 69.47 & \\
\hline & Technical & 11.00 & & 10.00 & & 75.00 & & 72.50 & \\
\hline \multirow{7}{*}{$\begin{array}{l}\text { DM prevents } \\
\text { activities of } \\
\text { daily living }\end{array}$} & Never & 12.17 & \multirow{7}{*}{$0.000^{*}$} & 10.24 & \multirow{7}{*}{$0.000^{*}$} & 74.17 & \multirow{7}{*}{0.291} & 73.33 & \multirow{7}{*}{$0.036^{*}$} \\
\hline & Rarely & 11.12 & & 11.60 & & 66.52 & & 65.83 & \\
\hline & Sometimes & 10.29 & & 12.29 & & 66.43 & & 71.79 & \\
\hline & Moderately & 8.68 & & 9.00 & & 70.36 & & 69.32 & \\
\hline & Mostly & 9.00 & & 8.38 & & 68.95 & & 71.07 & \\
\hline & Always & 8.75 & & 9.25 & & 70.00 & & 75.00 & \\
\hline & Everyday & 0 & & 11.00 & & 0 & & 70.00 & \\
\hline \multirow{4}{*}{$\begin{array}{l}\text { Ability to } \\
\text { manage } \\
\text { positively }\end{array}$} & Poor ability & 9.22 & \multirow{4}{*}{0.590} & 10.46 & \multirow{4}{*}{$0.058^{*}$} & 65.00 & \multirow{4}{*}{$0.006^{*}$} & 65.77 & \multirow{4}{*}{0.346} \\
\hline & Moderate ability & 9.88 & & 9.80 & & 67.01 & & 70.36 & \\
\hline & Good ability & 9.61 & & 10.57 & & 72.18 & & 70.89 & \\
\hline & Excellent ability & 0 & & 7.00 & & 0 & & 66.25 & \\
\hline \multirow{8}{*}{$\begin{array}{l}\text { Knowledge of } \\
\text { DM and its } \\
\text { management }\end{array}$} & Poor & 10.86 & \multirow{8}{*}{$0.001^{*}$} & 8.00 & \multirow{8}{*}{$0.003^{*}$} & 72.50 & \multirow{8}{*}{0.296} & 82.50 & \\
\hline & Fair & 11.45 & & 11.64 & & 64.09 & & 71.43 & \\
\hline & Satisfactory & 9.58 & & 11.16 & & 68.27 & & 65.20 & \\
\hline & Above average & 9.73 & & 9.00 & & 68.18 & & 70.47 & $0.050^{*}$ \\
\hline & Good & 8.96 & & 9.69 & & 69.45 & & 71.47 & \\
\hline & Very good & 10.43 & & 10.38 & & 70.36 & & 68.13 & \\
\hline & Excellent & 10.00 & & 12.33 & & 85.00 & & 73.33 & \\
\hline & Total & 9.72 & & 10.06 & & 69.13 & & 70.06 & \\
\hline
\end{tabular}

${ }^{*} p<0.05$ is the level of significance (sig).

they overcome challenges in coping with T2D. Results of the study were congruent with previous studies $[49,50]$ that show better self-care leads to improved QoL. In this study, men with T2D had low QoL which was consistent with a previous study [51].

In middle aged women, perceived diabetes did not prevent their activities of living, and they showed above average knowledge and management of diabetes. A strong effect was found for interactions between females and QoL due to higher schooling and ability to manage diabetes positively; while higher age, prevention of ADL, and knowledge/management of diabetes were significant with health state among women. SCA, diabetes education, and medication significantly predicted health state among women. Better physical activity among women contributes to higher QoL and had better understanding of their diabetes. These findings were consistent with other studies [52] that show younger age [53], education [54], longer duration of DM, fasting glucose levels [55], strong knowledge [56], and positive attitude [57-59] had significantly explained higher QoL scores.

Men had consistently lower QoL for all domains compared to women. Poor QoL can prevent men with T2D from achieving improved glucose control. Specific elements like ability to manage positively and BMI influenced QoL and health state among men as compared to women. In turn, low QoL affects HbAlc. Hence, better HbAlc and SCA are major predictors of QoL and health state. Independent predictors can have a contradictory effect on different aspects of QoL. Some studies show that men can experience more restrictions in daily life than women due to unexplained physical and emotional problems $[57,60]$.

An important finding is an impact of higher ability to manage diabetes positively and prevention of prevents activities of daily living that significantly predicted QoL; while BMI significantly predicted health state among men. The effects were stronger for those with high school and diploma level education and longer duration of diabetes, prevention 
TABLE 3: Clinical characteristics and total QOL and health state among men and women.

\begin{tabular}{|c|c|c|c|c|c|c|c|c|c|}
\hline \multirow{2}{*}{ Variables } & \multirow{2}{*}{ Categories } & \multicolumn{2}{|c|}{ Men QoL } & \multicolumn{2}{|c|}{ Women QoL } & \multicolumn{2}{|c|}{ Men health state } & \multicolumn{2}{|c|}{ Women health state } \\
\hline & & Mean & $\mathrm{Sig} / p$ & Mean & $\mathrm{Sig} / p$ & Mean & $\mathrm{Sig} / p$ & Mean & $\operatorname{Sig} / p$ \\
\hline \multirow{3}{*}{ Duration } & $0-9$ & 8.81 & \multirow{3}{*}{$0.000^{*}$} & 8.98 & \multirow{3}{*}{$0.002^{*}$} & 70.70 & \multirow{3}{*}{$0.013^{*}$} & 70.00 & \multirow{3}{*}{$0.001^{*}$} \\
\hline & $10-19$ & 10.15 & & 10.73 & & 69.55 & & 72.14 & \\
\hline & $20 \&$ above & 10.95 & & 10.36 & & 62.89 & & 63.80 & \\
\hline \multirow{2}{*}{ Self-care activities } & 0-3 days/week & 9.80 & \multirow{2}{*}{0.589} & 10.02 & \multirow{2}{*}{0.848} & 69.94 & \multirow{2}{*}{0.226} & 68.68 & \multirow{2}{*}{$0.035^{*}$} \\
\hline & 4-7 days/week & 9.60 & & 10.11 & & 67.82 & & 72.18 & \\
\hline \multirow{2}{*}{$\begin{array}{l}\text { Prior diabetes } \\
\text { education }\end{array}$} & No & 10.46 & \multirow{2}{*}{$0.002^{*}$} & 10.58 & \multirow{2}{*}{$0.056^{*}$} & 66.70 & \multirow{2}{*}{$0.036^{*}$} & 67.15 & \multirow{2}{*}{$0.002^{*}$} \\
\hline & Yes & 9.32 & & 9.68 & & 70.43 & & 72.12 & \\
\hline \multirow{3}{*}{ Medication } & $\mathrm{OH}$ & 10.09 & \multirow{3}{*}{$0.002^{*}$} & 10.40 & \multirow{3}{*}{$0.003^{*}$} & 69.55 & & 70.04 & \multirow{3}{*}{$0.003^{*}$} \\
\hline & Insulin & 9.03 & & 8.72 & & 68.44 & 0.686 & 70.16 & \\
\hline & $\mathrm{OH}$ and insulin & 8.20 & & 0 & & 67.00 & & 0 & \\
\hline \multirow{3}{*}{$\begin{array}{l}\text { Body mass index } \\
\left(\mathrm{kg} / \mathrm{m}^{2}\right)\end{array}$} & $<18.5 /$ Underweight & 9.75 & \multirow{3}{*}{0.875} & 10.00 & \multirow{3}{*}{0.885} & 66.25 & & 76.25 & \multirow{3}{*}{0.390} \\
\hline & 18.5-24.9/Healthy weight & 9.78 & & 9.98 & & 67.45 & $0.007^{*}$ & 70.24 & \\
\hline & 25.0-29.9/Overweight & 9.58 & & 10.23 & & 73.14 & & 69.15 & \\
\hline \multirow{2}{*}{ HbAlc } & $<7 \%$ & 9.52 & \multirow{2}{*}{0.371} & 9.76 & \multirow{2}{*}{0.174} & 69.54 & \multirow{2}{*}{0.708} & 70.95 & \multirow{2}{*}{0.241} \\
\hline & $>7 \%$ & 9.84 & & 10.40 & & 68.88 & & 69.04 & \\
\hline
\end{tabular}

${ }^{*} p<0.05$ is the level of significance (sig).

TABLE 4: Combined effect of predictors on QoL and health state: multivariate tests/GLM.

\begin{tabular}{|c|c|c|c|c|c|c|}
\hline \multirow{2}{*}{$\begin{array}{l}\text { Wilks's lambda } \\
\text { Effect }\end{array}$} & \multicolumn{3}{|c|}{ Men } & \multicolumn{3}{|c|}{ Women } \\
\hline & Value & $F$ & Sig./p & Value & $F$ & Sig. $/ p$ \\
\hline Intercept & 0.586 & 45.957 & $0.000^{*}$ & 0.607 & 46.602 & $0.000^{*}$ \\
\hline Age & 0.965 & 2.391 & $0.050^{*}$ & 0.804 & 17.581 & $0.000^{*}$ \\
\hline Schooling & 0.995 & 0.307 & 0.736 & 0.996 & 0.300 & 0.741 \\
\hline Years of diabetes & 0.927 & 5.155 & $0.007^{*}$ & 0.977 & 1.706 & 0.185 \\
\hline Self-care activities & 0.996 & 0.252 & 0.778 & 0.974 & 1.950 & 0.146 \\
\hline Diabetes education program & 0.937 & 4.340 & $0.015^{*}$ & 0.961 & 2.892 & $0.050^{*}$ \\
\hline DM prevents activities of daily living & 0.898 & 7.365 & $0.001^{*}$ & 0.983 & 1.235 & 0.294 \\
\hline Ability to manage positively & 0.953 & 3.210 & $0.044^{*}$ & 0.998 & 0.112 & 0.894 \\
\hline Knowledge of diabetes/management & 0.995 & 0.306 & 0.737 & 1.000 & 0.034 & 0.966 \\
\hline Medications & 0.981 & 1.249 & 0.290 & 0.993 & 0.528 & 0.591 \\
\hline Body mass index & 0.926 & 5.176 & $0.007^{*}$ & 0.968 & 2.377 & $0.050^{*}$ \\
\hline HbAlc & 0.993 & 0.428 & 0.653 & 0.988 & 0.877 & 0.418 \\
\hline
\end{tabular}

${ }^{*} p<0.05$ is the level of significance (sig).

Design: intercept + age + schooling + duration of diabetes + self-care activities + diabetes education program + perceiving DM prevents activities of daily living + ability to manage positively + knowledge of diabetes and its management + medications + BMI + HbAlc.

of activities of daily living, ability to manage positively, and body mass index which were significant determinants among men. Some men have more self-confidence in their ability to manage diabetes and are less likely to be depressed or anxious. Hence, good knowledge and a positive attitude are predictors of adherence to self-care and promote QoL. Men with higher educational levels, strong knowledge, and positive attitude had a higher probability of attaining greater QoL scores [56]. Age [61], psychological perception, SCA, HbAlc, and lower levels of physical activity [62] were significantly associated with higher QoL among men.

The most striking difference was that women had higher QoL scores and health state for higher age and low BMI and adhered better to oral medications and SCA. This finding reflects the inclination of women with higher education to participate in their own self-care. Age, duration of diabetes, diabetes education, and ability to manage diabetes had higher QoL and health state among men. Hence, chronicity of T2D has a differential impact on QoL and health state among women and men. Patients of both genders with lower HbAlc values were shown to have better QoL [63]. Similar studies show high BMI is a strong predictor of decreased QoL $[57,64]$ and lower BMI was associated with higher QoL [65]. Insulin and higher BMI were associated with lower QoL [33, 61, 63]. QoL and health state scores were lower in women compared with men and lower with longer duration of T2D [54]. HbA1c 
TABLE 5: Overall model significance and tests of between-subjects effects.

\begin{tabular}{|c|c|c|c|c|c|c|c|}
\hline \multirow{2}{*}{ Source } & \multirow{2}{*}{$\begin{array}{l}\text { Dependent variable } \\
\text { Outcomes }\end{array}$} & \multicolumn{3}{|c|}{ Men } & \multicolumn{3}{|c|}{ Women } \\
\hline & & Mean Square & $F$ & Sig./p & Mean Square & $F$ & Sig./p \\
\hline \multirow{2}{*}{ Corrected model } & QoL & 20.219 & 6.615 & 0.000 & 36.888 & 5.822 & 0.000 \\
\hline & Health state & 307.235 & 3.550 & 0.000 & 204.893 & 2.146 & 0.021 \\
\hline \multirow{2}{*}{ Intercept } & QoL & 152.364 & 49.849 & 0.000 & 184.703 & 29.152 & 0.000 \\
\hline & Health state & 3067.884 & 35.452 & 0.000 & 5790.067 & 60.638 & 0.000 \\
\hline \multirow{2}{*}{ Age } & QoL & 0.798 & 0.261 & 0.610 & 181.721 & 28.681 & $0.000^{*}$ \\
\hline & Health state & 376.955 & 4.356 & $0.039^{*}$ & 524.830 & 5.496 & $0.020^{*}$ \\
\hline \multirow{2}{*}{ Schooling } & QoL & 0.509 & 0.166 & 0.684 & 0.012 & 0.002 & 0.966 \\
\hline & Health state & 42.830 & 0.495 & 0.483 & 57.694 & 0.604 & 0.438 \\
\hline \multirow{2}{*}{ Years of diabetes } & QoL & 16.577 & 5.424 & $0.021^{*}$ & 20.945 & 3.306 & $0.050^{*}$ \\
\hline & Health state & 501.693 & 5.798 & $0.017^{*}$ & 18.774 & 0.197 & 0.658 \\
\hline \multirow{2}{*}{ Self-care activities } & QoL & 0.750 & 0.245 & 0.621 & 4.686 & 0.740 & 0.391 \\
\hline & Health state & 19.141 & 0.221 & 0.639 & 290.368 & 3.041 & $0.05^{*}$ \\
\hline \multirow{2}{*}{ Diabetes education } & QoL & 5.044 & 1.650 & 0.201 & 18.808 & 2.968 & $0.05^{*}$ \\
\hline & Health state & 658.313 & 7.607 & $0.007^{*}$ & 298.142 & 3.122 & $0.050^{*}$ \\
\hline \multirow{2}{*}{ DM prevents activities of daily living } & QoL & 43.917 & 14.369 & $0.000^{*}$ & 9.693 & 1.530 & 0.218 \\
\hline & Health state & 12.687 & 0.147 & 0.702 & 102.130 & 1.070 & 0.303 \\
\hline \multirow{2}{*}{ Ability to manage positively } & QoL & 1.641 & 0.537 & 0.465 & 0.253 & 0.040 & 0.842 \\
\hline & Health state & 485.729 & 5.613 & $0.019^{*}$ & 18.416 & 0.193 & 0.661 \\
\hline \multirow{2}{*}{ Knowledge of diabetes and its management } & QoL & 1.706 & 0.558 & 0.456 & 0.045 & 0.007 & 0.933 \\
\hline & Health state & 2.853 & 0.033 & 0.856 & 5.747 & 0.060 & 0.807 \\
\hline \multirow{2}{*}{ Medications } & QoL & 7.523 & 2.461 & 0.119 & 0.206 & 0.033 & 0.857 \\
\hline & Health state & 1.027 & 0.012 & 0.913 & 99.743 & 1.045 & 0.308 \\
\hline \multirow{2}{*}{ Body mass index } & QoL & 0.014 & 0.005 & 0.946 & 15.544 & 2.453 & 0.119 \\
\hline & Health state & 893.502 & 10.325 & $0.002^{*}$ & 243.893 & 2.554 & 0.112 \\
\hline \multirow{2}{*}{ HbAlc } & QoL & 2.173 & 0.711 & 0.401 & 10.261 & 1.620 & 0.205 \\
\hline & Health state & 17.990 & 0.208 & 0.649 & 18.486 & 0.194 & 0.661 \\
\hline
\end{tabular}

Generalized linear model: ${ }^{*} p<0.05$ is the level of significance (sig). Computed using alpha $=0.05$.

Men: QoL $R^{2}=0.357$ (adjusted $R^{2}=0.303$ ); health state $R^{2}=0.230$ (adjusted $R^{2}=0.165$ ).

Women: QoL $R^{2}=0.306$ (adjusted $R^{2}=0.254$ ); health state $R^{2}=0.140$ (adjusted $R^{2}=0.075$ ).

and QoL have a significant association in previous studies $[66,67]$. Higher age, income, and education had better QoL among women $[56,61,67,68]$. Men and women who have good health have significant health states with T2D [52, 69].

The study limitations are interactive effects of psychological and clinical predictors that may be relevant for comprehensive understanding of the impact on the domains of health-related QoL among men and women.

\section{Conclusions}

The amount of variance influenced by the personal and clinical factors and explained in the GLM is useful in understanding how HRQoL influences Omani men and women. Poor glycemic control increases the risk of developing long term complications of T2D, which causes poor health state and QoL. Maintaining HbAlc within a desirable range is an indicator of good glycemic control and was a contributor to better QoL.

The assessment of QoL and health state is a key component of the self-care management model (Figure 1).
This assessment is culturally specific and may assist in early identification to allow for appropriate self-care among individuals with T2D who are at risk for decreased QoL. This study gives useful information to help design appropriate culturally specific interventions related to various aspects of QoL [70]. The SCM model approach indicates that adults need to use their self-care behaviors for goal attainment and to take control of T2D, thus enhancing HRQoL.

This study provides important QoL evidence that may help the diabetes nurse educator (DNE) to identify adults who are at risk of low QoL and develop interventions for healthy lifestyle behaviors based on personal needs, clinical characteristics, and health state. The DNE can educate assist in motivating the patient with T2D to control blood glucose levels, have an annual screening examination, report any changes in health immediately, and engage in rigorous SCM. An effective SCM model empowers men and women in proactively managing $\mathrm{T} 2 \mathrm{D}$ and finding ways to overcome the problems with mobility, usual care, self-care, anxiety, and pain. SCM interventions by the DNE should be tailored to the individual taking into account personal needs and motivation 
to change as well as clinical factors that influence better QoL (Figure 1). The nurse as an educator has an opportunity to positively influence outcomes (QoL and health state) by using effective behavioral skills and a collaborative health care approach.

\section{Summary Box}

(1) What does this paper contribute to the community? Women had higher mean QoL scores for age, schooling, prevention of activities of daily living, ability to manage positively, and knowledge of diabetes and its management.

(2) Women had higher mean health state scores for age and perceiving DM prevents activities of daily living and knowledge of diabetes and its management.

(3) Age, duration of diabetes, diabetes education, selfcare activities, ability to manage diabetes positively, and BMI were significant predictors of QoL and health state among women and men.

\section{Conflict of Interests}

There are no organizations or communities with conflict of interests or coveting interests related to the study. The coauthors declare that they have no competing interests.

\section{Authors' Contribution}

Melba Sheila D'Souza, Ramesh Venkatesaperumal, and Subrahmanya Nairy Karkada provided substantial contributions to conception and design, acquisition of data, and analysis and interpretation of data. Ramesh Venkatesaperumal, Melba Sheila D'Souza, Susan D. Ruppert, and Devakirubai Jacob participated in drafting the article and revising it critically for important intellectual inquiry. All the authors agreed on the final version of the paper to be published.

\section{Acknowledgments}

The authors gratefully acknowledge the content experts for the valuable discussions and Reginald Roach for editing the paper. The source of funding was College of Nursing, Sultan Qaboos University DF/CN/06/10.

\section{References}

[1] J. A. Al-Lawati, A. M. Al Riyami, A. J. Mohammed, and P. Jousilahti, "Increasing prevalence of diabetes mellitus in Oman," Diabetic Medicine, vol. 19, no. 11, pp. 954-957, 2002.

[2] International Diabetes Federation, About Diabetes, 2013, http:// www.idf.org/about-diabetes.

[3] D. W. Lam and D. LeRoith, "The worldwide diabetes epidemic," Current Opinion in Endocrinology, Diabetes \& Obesity, vol. 19, no. 2, pp. 93-96, 2012.

[4] K. G. M. M. Alberti, P. Zimmet, and J. Shaw, "Metabolic syndrome-a new world-wide definition. A consensus statement from the International Diabetes Federation," Diabetic Medicine, vol. 23, no. 5, pp. 469-480, 2006.
[5] A. Al-Riyami, "Type 2 diabetes in Oman: can we learn from the Lancet editorial," Oman Medical Journal, vol. 23, no. 3, p. 153, 2010.

[6] D. R. Whiting, L. Guariguata, C. Weil, and J. Shaw, "IDF Diabetes Atlas: global estimates of the prevalence of diabetes for 2011 and 2030," Diabetes Research and Clinical Practice, vol. 94, no. 3, pp. 311-321, 2011.

[7] J. A. Al-Lawati, M. N. Barakat, M. Al-Maskari, M. K. Elsayed, A. M. Al-Lawati, and A. J. Mohammed, "HbAlc levels among primary healthcare patients with type 2 diabetes mellitus in Oman," Oman Medical Journal, vol. 27, no. 6, pp. 465-470, 2012.

[8] M. A. Al Shafaee, S. Al-Shukaili, S. G. A. Rizvi et al., "Knowledge and perceptions of diabetes in a semi-urban Omani population," BMC Public Health, vol. 8, no. 1, article 249, 2008.

[9] A. Al-Shookri, G. L. Khor, Y. M. Chan, S. C. Loke, and M. AlMaskari, “Type 2 diabetes in the Sultanate of Oman," Malaysian Journal of Nutrition, vol. 17, no. 1, pp. 129-141, 2011.

[10] A. Al-Mandhari, I. Al-Zakwani, A. Al-Hasn, and N. Al-Sumri, "Assessment of perceived health status in hypertensive and diabetes mellitus patients at primary health centers in Oman," International Journal of Preventive Medicine, vol. 2, no. 4, pp. 256-263, 2011.

[11] L. Guariguata, "By the numbers: new estimates from the IDF Diabetes Atlas Update for 2012," Diabetes Research and Clinical Practice, vol. 98, no. 3, pp. 524-525, 2012.

[12] J. A. Al-Lawati, M. N. Barakat, I. Al-Zakwani et al., "Control of risk factors for cardiovascular disease among adults with previously diagnosed type 2 diabetes mellitus: a descriptive study from a middle eastern Arab population," Open Cardiovascular Medicine Journal, vol. 6, no. 1, pp. 133-140, 2012.

[13] Ministry of Health, World Health Survey: Oman, D.G.o.P. Department of Research, Ministry of Health Publications, 2008.

[14] World Health Organization, "Development of the World Health Organization WHOQOL-BREF quality of life assessment," Psychological Medicine, vol. 28, no. 3, pp. 551-558, 1998.

[15] I. Waernbaum, G. Blohmé, J. Östman et al., "Excess mortality in incident cases of diabetes mellitus aged 15 to 34 years at diagnosis: a population-based study (DISS) in Sweden," Diabetologia, vol. 49, no. 4, pp. 653-659, 2006.

[16] R. M. Anderson and M. M. Funnell, "Patient empowerment: myths and misconceptions," Patient Education and Counseling, vol. 79, no. 3, pp. 277-282, 2010.

[17] S. Wild, G. Roglic, A. Green, R. Sicree, and H. King, "Global prevalence of diabetes: estimates for the year 2000 and projections for 2030," Diabetes Care, vol. 27, no. 5, pp. 1047-1053, 2004.

[18] T. Anderbro, S. Amsberg, U. Adamson et al., "Fear of hypoglycaemia in adults with Type 1 diabetes," Diabetic Medicine, vol. 27, no. 10, pp. 1151-1158, 2010.

[19] M. Grey, S. S. Jaser, R. Whittemore, S. Jeon, and E. Lindemann, "Coping skills training for parents of children with type 1 diabetes: 12-month outcomes," Nursing Research, vol. 60, no. 3, pp. 173-181, 2011.

[20] Y. El Achhab, C. Nejjari, M. Chikri, and B. Lyoussi, "Diseasespecific health-related quality of life instruments among adults diabetic: a systematic review," Diabetes Research and Clinical Practice, vol. 80, no. 2, pp. 171-184, 2008.

[21] H. Sakamaki, S. Ikeda, N. Ikegami et al., "Measurement of HRQL using EQ-5D in patients with type 2 diabetes mellitus in Japan," Value in Health, vol. 9, no. 1, pp. 47-53, 2006.

[22] V. Sparring, L. Nyström, R. Wahlström, P. M. Jonsson, J. Östman, and K. Burström, "Diabetes duration and healthrelated quality of life in individuals with onset of diabetes in 
the age group 15-34 years-a Swedish population-based study using EQ-5D," BMC Public Health, vol. 13, no. 1, article 377, 2013.

[23] A. Z. Fu, Y. Qiu, L. Radican, and N. Luo, "Marginal differences in health-related quality of life of diabetic patients with and without macrovascular comorbid conditions in the United States," Quality of Life Research, vol. 20, no. 6, pp. 825-832, 2011.

[24] O. Solli, K. Stavem, and I. S. Kristiansen, "Health-related quality of life in diabetes: the associations of complications with EQ-5D scores," Health and Quality of Life Outcomes, vol. 8, article 18, 2010.

[25] C. J. Currie, C. D. Poole, A. Woehl et al., “The health-related utility and health-related quality of life of hospital-treated subjects with type 1 or type 2 diabetes with particular reference to differing severity of peripheral neuropathy," Diabetologia, vol. 49, no. 10, pp. 2272-2280, 2006.

[26] W. J. Lee, K.-H. Song, J. H. Noh, Y. J. Choi, and M.-W. Jo, "Health-related quality of life using the EuroQol 5D questionnaire in Korean patients with type 2 diabetes," Journal of Korean Medical Science, vol. 27, no. 3, pp. 255-260, 2012.

[27] M. J. Naughton, A. M. Ruggiero, J. M. Lawrence et al., "Healthrelated quality of life of children and adolescents with type 1 or type 2 diabetes mellitus: SEARCH for diabetes in youth study," Archives of Pediatrics \& Adolescent Medicine, vol. 162, no. 7, pp. 649-657, 2008.

[28] Y. J. Choi, M. S. Lee, S. Y. An et al., “The relationship between diabetes mellitus and health-related quality of life in Korean adults: the fourth Korea National Health and Nutrition Examination Survey (2007-2009)," Diabetes \& Metabolism Journal, vol. 35 , no. 6 , pp. 587-594, 2011.

[29] W. L. Bennett, P. Ouyang, A. W. Wu, B. B. Barone, and K. J. Stewart, "Fatness and fitness: how do they influence healthrelated quality of life in type 2 diabetes mellitus?" Health and Quality of Life Outcomes, vol. 6, article 110, 2008.

[30] S. A. Williams, L. Shi, S. K. Brenneman, J. C. Johnson, J. C. Wegner, and V. Fonseca, "The burden of hypoglycemia on healthcare utilization, costs, and quality of life among type 2 diabetes mellitus patients," Journal of Diabetes and Its Complications, vol. 26, no. 5, pp. 399-406, 2012.

[31] M.-F. Huang, M. Courtney, H. Edwards, and J. McDowell, "Factors that affect health outcomes in adults with type 2 diabetes: a cross-sectional study," International Journal of Nursing Studies, vol. 47, no. 5, pp. 542-549, 2010.

[32] A. A. Papadopoulos, N. Kontodimopoulos, A. Frydas, E. Ikonomakis, and D. Niakas, "Predictors of health-related quality of life in type II diabetic patients in Greece," BMC Public Health, vol. 7, article 186, 2007.

[33] V. D. Sousa and J. A. Zauszniewski, "Toward a theory of diabetes self-care management," Journal of Theory Construction \& Testing, vol. 9, no. 2, pp. 61-67, 2005.

[34] M. S. D’Souza, R. Venkatesaperumal, S. N. Karkada, and A. Amirtharaj, "Determinants of glycosylated haemaglobin among adults with type 2 diabetes mellitus in Muscat," Journal of Diabetes and Metabolism, vol. 4, no. 5, 2013.

[35] Y. Liu, M. Maier, Y. Hao, Y. Chen, Y. Qin, and R. Huo, "Factors related to quality of life for patients with type 2 diabetes with or without depressive symptoms-results from a communitybased study in China," Journal of Clinical Nursing, vol. 22, no. 1-2, pp. 80-88, 2013.

[36] M.-C. Huang, C.-H. Hung, J. Stocker, and L.-C. Lin, "Outcomes for type 2 diabetes mellitus patients with diverse regimens," Journal of Clinical Nursing, vol. 22, no. 13-14, pp. 1899-1906, 2013.
[37] I.-C. Huang, J.-H. Liu, A. W. Wu, M.-Y. Wu, W. Leite, and C.C. Hwang, "Evaluating the reliability, validity and minimally important difference of the Taiwanese version of the diabetes quality of life (DQOL) measurement," Health and Quality of Life Outcomes, vol. 6, article 87, 2008.

[38] F. Faul, E. Erdfelder, A. Buchner, and A.-G. Lang, "Statistical power analyses using $G^{\star}$ Power 3.1: tests for correlation and regression analyses," Behavior Research Methods, vol. 41, no. 4, pp. 1149-1160, 2009.

[39] S. Amsberg, T. Anderbro, R. Wredling et al., "A cognitive behavior therapy-based intervention among poorly controlled adult type 1 diabetes patients-a randomized controlled trial," Patient Education and Counseling, vol. 77, no. 1, pp. 72-80, 2009.

[40] EuroQol, "EuroQol-a new facility for the measurement of health-related quality of life," Health Policy, vol. 13, no. 3, pp. 199-208, 1990.

[41] G. R. Barton, T. H. Sach, M. Doherty, A. J. Avery, C. Jenkinson, and K. R. Muir, "An assessment of the discriminative ability of the EQ-5Dindex, SF-6D, and EQ VAS, using sociodemographic factors and clinical conditions," European Journal of Health Economics, vol. 9, no. 3, pp. 237-249, 2008.

[42] D. J. Toobert, S. E. Hampson, and R. E. Glasgow, "The summary of diabetes self-care activities measure: results from 7 studies and a revised scale," Diabetes Care, vol. 23, no. 7, pp. 943-950, 2000.

[43] E. S. Ford, "Prevalence of the metabolic syndrome defined by the international diabetes federation among adults in the U.S.," Diabetes Care, vol. 28, no. 11, pp. 2745-2749, 2005.

[44] J. B. Meigs, P. W. F. Wilson, C. S. Fox et al., "Body mass index, metabolic syndrome, and risk of type 2 diabetes or cardiovascular disease," The Journal of Clinical Endocrinology of Metabolism, vol. 91, no. 8, pp. 2906-2912, 2006.

[45] B. G. Tabachnick and L. S. Fidell, Using Multivariate Statistics, Pearson Education, Boston, Mass, USA, 2007.

[46] K. P. Weinfurt, "Repeated measures analysis: ANOVA, MANOVA, and HLM," in Reading and Understanding MORE Multivariate Statistics, L. G. Laurence and P. Yarnold, Eds., pp. 317-361, American Psychological Association, Washington, DC, USA, 2000.

[47] H. J. Keselman, C. J. Huberty, R. A. Cribbie et al., "Statistical practices of educational researchers: An analysis of their ANOVA, MANOVA, and ANCOVA analyses," Review of Educational Research, vol. 68, no. 3, pp. 350-386, 1998.

[48] J. P. Stevens, Applied Multivariate Statistics for the Social Sciences, (Applied Multivariate STATS), Lawrence Erlbaum Associates, Hillsdale, NJ, USA, 2001.

[49] C. Li, E. S. Ford, A. H. Mokdad, R. Jiles, and W. H. Giles, "Clustering of multiple healthy lifestyle habits and healthrelated quality of life among U.S. adults with diabetes," Diabetes Care, vol. 30, no. 7, pp. 1770-1776, 2007.

[50] M. S. D’Souza, S. N. Karkada, and G. Somayaji, "Factors associated with health-related quality of life among Indian women in mining and agriculture," Health and Quality of Life Outcomes, vol. 11, no. 1, article 9, 2013.

[51] M. Kazemi-Galougahi, H. Ghaziani, H. Ardebili, and M. Mahmoudi, "Quality of life in type 2 diabetic patients and related effective factors," Indian Journal of Medical Sciences, vol. 66, no. 9-10, pp. 230-237, 2012.

[52] M. S. D’Souza, S. N. Karkada, N. P. Hanrahan, R. Venkatesaperumal, and A. Amirtharaj, "Do perceptions of empowerment affect glycemic control and self-care among adults with type 2 
diabetes?" Global Journal of Health Science, vol. 7, no. 5, article 80, 2015.

[53] A. Eljedi, R. T. Mikolajczyk, A. Kraemer, and U. Laaser, "Healthrelated quality of life in diabetic patients and controls without diabetes in refugee camps in the Gaza strip: a cross-sectional study," BMC Public Health, vol. 6, article 268, 2006.

[54] M. Javanbakht, F. Abolhasani, A. Mashayekhi, H. R. Baradaran, and Y. Jahangiri noudeh, "Health related quality of life in patients with type 2 diabetes mellitus in Iran: a national survey," PLoS ONE, vol. 7, no. 8, Article ID e44526, 2012.

[55] M. S. D’Souza, S. N. Karkada, G. Somayaji, and R. Venkatesaperumal, "Women's well-being and reproductive health in Indian mining community: need for empowerment," Reproductive Health, vol. 10, no. 1, article 24, 2013.

[56] Y. V. Martínez, C. A. Prado-Aguilar, R. A. Rascón-Pacheco, and J. J. Valdivia-Martínez, "Quality of life associated with treatment adherence in patients with type 2 diabetes: a cross-sectional study," BMC Health Services Research, vol. 8, no. 1, article 164, 2008.

[57] I. Svenningsson, B. Marklund, S. Attvall, and B. Gedda, "Type 2 diabetes: perceptions of quality of life and attitudes towards diabetes from a gender perspective," Scandinavian Journal of Caring Sciences, vol. 25, no. 4, pp. 688-695, 2011.

[58] L. P. Jelsness-Jørgensen, L. Ribu, T. Bernklev, and B. A. Moum, "Measuring health-related quality of life in non-complicated diabetes patients may be an effective parameter to assess patients at risk of a more serious disease course: a crosssectional study of two diabetes outpatient groups," Journal of Clinical Nursing, vol. 20, no. 9-10, pp. 1255-1263, 2011.

[59] G. Kacerovsky-Bielesz, S. Lienhardt, M. Hagenhofer et al., "Sexrelated psychological effects on metabolic control in type 2 diabetes mellitus," Diabetologia, vol. 52, no. 5, pp. 781-788, 2009.

[60] P. Tenzer-Iglesias, "Type 2 diabetes mellitus in women," The Journal of Family Practice, vol. 63, no. 2, pp. S21-S26, 2014.

[61] I. Imayama, R. C. Plotnikoff, K. S. Courneya, and J. A. Johnson, "Determinants of quality of life in adults with type 1 and type 2 diabetes," Health and Quality of Life Outcomes, vol. 9, article 115, 2011.

[62] J.-Y. Cong, Y. Zhao, Q.-Y. Xu, C.-D. Zhong, and Q.-L. Xing, "Health-related quality of life among Tianjin Chinese patients with type 2 diabetes: a cross-sectional survey," Nursing \& Health Sciences, vol. 14, no. 4, pp. 528-534, 2012.

[63] Y. T. Shim, J. Lee, M. P. H. S. Toh, W. E. Tang, and Y. Ko, "Healthrelated quality of life and glycaemic control in patients with Type 2 diabetes mellitus in Singapore," Diabetic Medicine, vol. 29, no. 8, pp. e241-e248, 2012.

[64] M. Sundaram, J. Kavookjian, J. H. Patrick, L.-A. Miller, S. S. Madhavan, and V. Scott, "Quality of life, health status and clinical outcomes in Type 2 diabetes patients," Quality of Life Research, vol. 16, no. 2, pp. 165-177, 2007.

[65] C. K. H. Wong, Y. Y. C. Lo, W. H. T. Wong, and C. S. C. Fung, "The associations of body mass index with physical and mental aspects of health-related quality of life in Chinese patients with type 2 diabetes mellitus: results from a cross-sectional survey," Health \& Quality of Life Outcomes, vol. 11, no. 1, article 142, 9 pages, 2013.

[66] R.-H. Wang, L.-C. Wu, and H.-Y. Hsu, "A path model of healthrelated quality of life in Type 2 diabetic patients: a crosssectional study in Taiwan," Journal of Advanced Nursing, vol. 67, no. 12, pp. 2658-2667, 2011.
[67] H.-F. Wang and M. C. Yeh, "The quality of life of adults with type 2 diabetes in a hospital care clinic in Taiwan," Quality of Life Research, vol. 22, no. 3, pp. 577-584, 2013.

[68] W. Bani-Issa, "Evaluation of the health-related quality of life of emirati people with diabetes: integration of sociodemographic and disease-related variables," Eastern Mediterranean Health Journal, vol. 17, no. 11, pp. 825-830, 2011.

[69] U. W. Jayasinghe, M. F. Harris, J. Taggart, B. Christl, and D. A. Black, "Gender differences in health-related quality of life of Australian chronically-ill adults: patient and physician characteristics do matter," Health and Quality of Life Outcomes, vol. 11, no. 1, article 102, 2013.

[70] M. S. DeSouza and K. S. Nairy, "An interventional study on the health promoting behaviours of adults with diabetes," Clinical Effectiveness in Nursing, vol. 8, no. 2, pp. 68-80, 2004. 


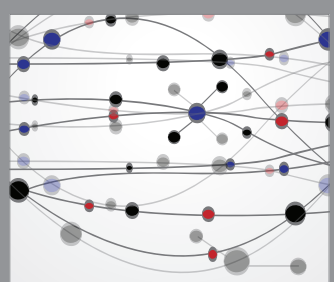

The Scientific World Journal
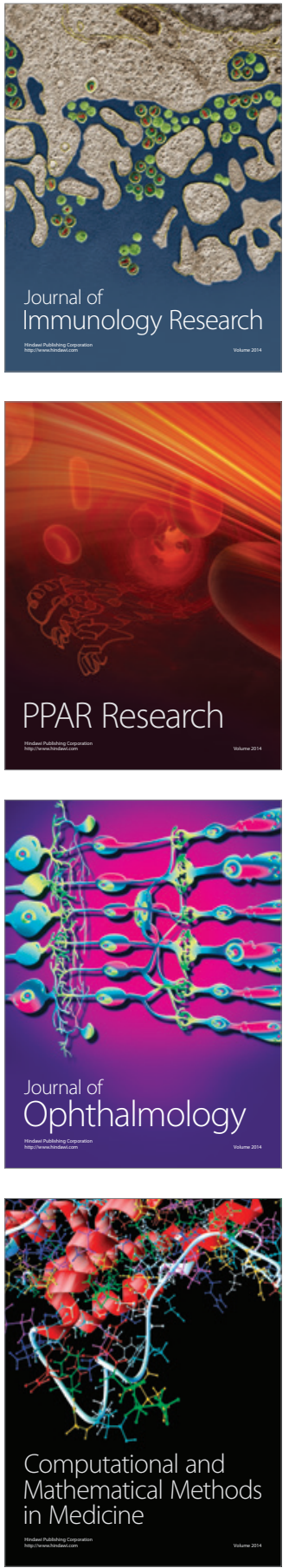

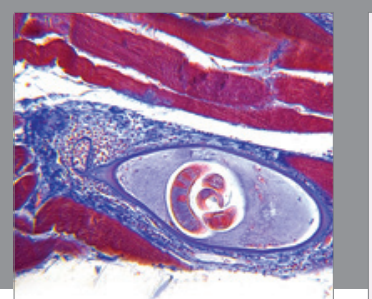

Gastroenterology Research and Practice

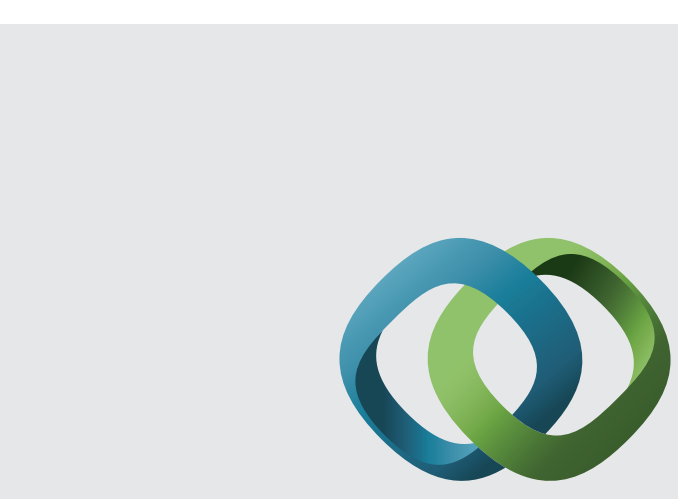

\section{Hindawi}

Submit your manuscripts at

http://www.hindawi.com
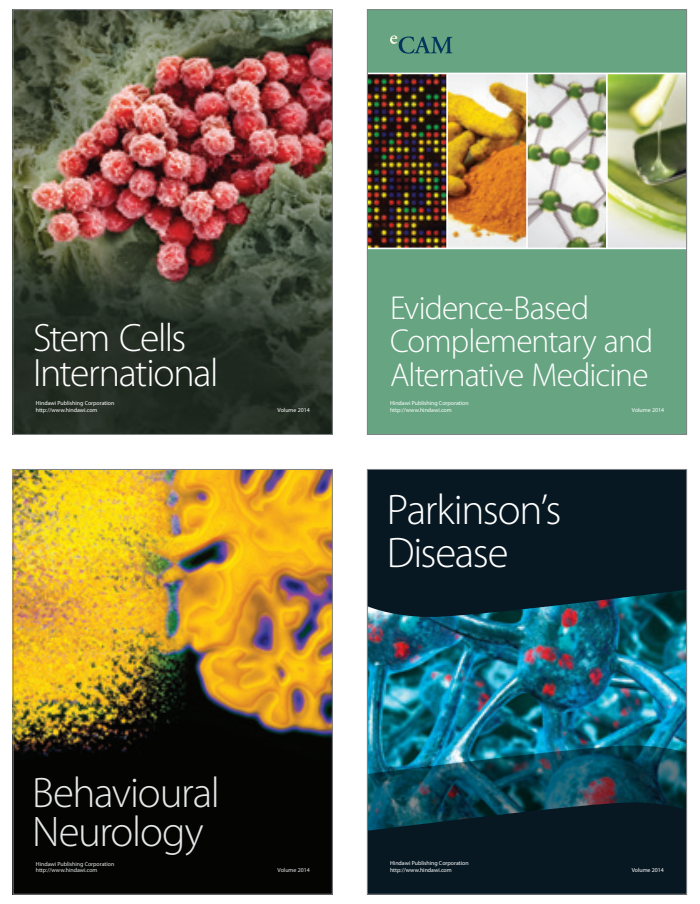
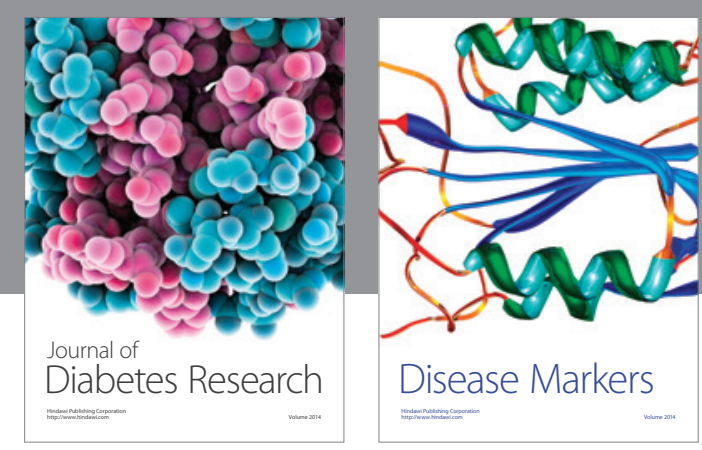

Disease Markers
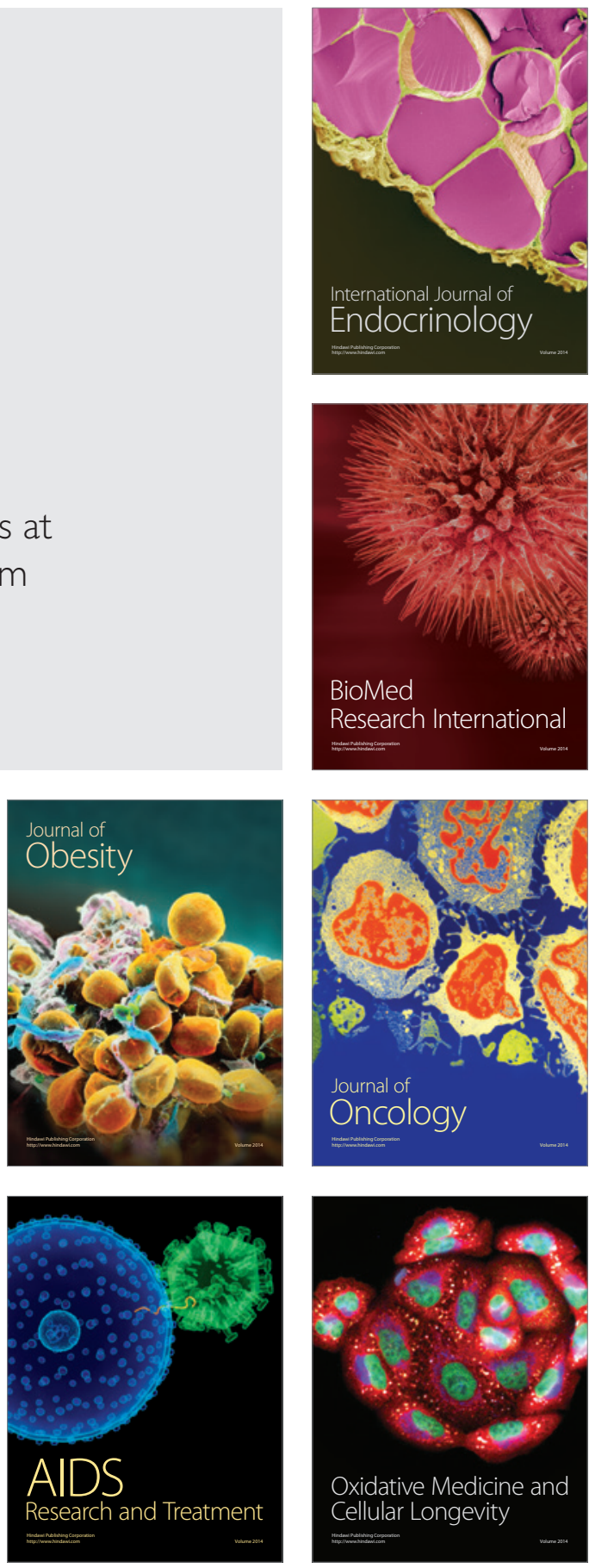